\title{
Influence of Humidity State on Dynamic Resilient Modulus of Subgrade Soils: Considering Repeated Wetting-Drying Cycles
}

\author{
Gongfeng Xin, ${ }^{1}$ Anshun Zhang $\mathbb{D}^{2}{ }^{2}$ Zijian Wang, ${ }^{1}$ Quanjun Shen, ${ }^{1}$ and Minghao $M u^{1}$ \\ ${ }^{1}$ Shandong Hi-Speed Group Innovation Research Institute, Jinan 250098, China \\ ${ }^{2}$ National Engineering Laboratory of Highway Maintenance Technology, Changsha University of Science \& Technology, \\ Changsha 410114, China
}

Correspondence should be addressed to Anshun Zhang; zas@stu.csust.edu.cn

Received 20 August 2021; Accepted 25 November 2021; Published 14 December 2021

Academic Editor: Abílio De Jesus

Copyright (c) 2021 Gongfeng Xin et al. This is an open access article distributed under the Creative Commons Attribution License, which permits unrestricted use, distribution, and reproduction in any medium, provided the original work is properly cited.

\begin{abstract}
The service performance of subgrade depends on the dynamic resilient modulus $\left(M_{R}\right)$ of subgrade soils. Meanwhile, due to complicated conditions such as rainfall infiltration, high temperature evaporation, and groundwater level fluctuations, it can be safely said that the humidity state and repeated wetting-drying (WD) cycles affect the $M_{R}$ of subgrade soils. The object of this study is to conduct a series of dynamic triaxial tests after WD cycles to investigate the characteristics of the $M_{R}$ under various factors. The main results are as follows: (i) the $M_{R}$ decreased with the increase of deviator stress and rose with the growth of confining pressure; (ii) the humidification effect caused by the increase in moisture content attenuated the $M_{R}$; (iii) the accumulation of WD cycles damaged the $M_{R}$; however the decline rate was gradually retarded until it was stable with WD cycles 5 times; (iv) the satisfactory prediction model for the $M_{R}$ of subgrade soils considering WD cycles was proposed and verified. It is expected that the findings can provide valuable contributions for road engineering.
\end{abstract}

\section{Introduction}

The dynamic resilient modulus $\left(M_{R}\right)$ is a key parameter to characterize the stiffness characteristics of subgrade soils $[1,2]$, and it is employed as a basic input for determining the pavement structure thickness and combination method, for example, in the design standard of asphalt pavement in China (JTG D50-2017) and the guide of the American Association of State Highway and Transportation Officials (AASHTO 2002). Moreover, considering the stability and durability during the operation period, in addition to meeting stiffness requirements, the influence due to complex working environments on the service performance of road materials such as asphalt mixtures [3,4], graded crushed rocks [5], and subgrade soils [6] is also a crucial issue that cannot be ignored. One of the universal occurrences is the change in the humidity of subgrade soils caused by a serious of reasons such as rainfall infiltration. According to longterm field tests data, the humidity of subgrade soils is not constant but gradually exceeds to the optimal moisture content (OMC) and eventually stabilized $[7,8]$. The harmful wetting effect attenuates the $M_{R}$ of subgrade soils with varying degrees, as many pavement diseases are attributed to this phenomenon, e.g., rutting [9], cracking [10], and bulge [11]. Therefore, it is of great significance to research the influence of humidity state on $M_{R}$ of subgrade soils.

At present, researchers have carried out numerous studies on the influence of humidity changes on $M_{R}$ of subgrade soils. Through two-year on-site monitoring, Elliott et al. [12] found that the actual moisture content of the subgrade soils progressively increased to 1.1 OMC. Subsequently, Zhang et al. [13] conducted soils humidity surveys on several expressways in southern China and reported that the moisture content of the subgrade soils continued to increase and finally stabilized at around $116 \%$ OMC. On this basis, they prepared high plasticity clays specimens under the moisture content conditions of 0.9 OMC, OMC, 1.1 OMC, 1.2 OMC, and 1.3 OMC, respectively, and performed corresponding repeated loading triaxial (RLT) tests [14]. The results showed that, under the given stress and compaction 
state, the increase in the moisture content of the specimen reduced the $M_{R}$. This rule was observed in the test results of Yao et al. [15] and Han et al. [16] for low liquid limit clays and seven different Canadian clays, respectively. For low liquid limit clays specimens with various moisture contents (OMC - 2\%, OMC, and OMC + 2\%) subjected to freezethaw cycles, Zhao et al. [17] claimed that whether it is a closed or open freezing method, the higher the moisture content, the lower the $M_{R}$, but the degree of attenuation is different. Zhang et al. [18] also used this level of moisture content to compact coarse grained fillers and organized RLT tests. The results captured the weakening effect of humidity growth on the $M_{R}$, in agreement with the findings on unbonded granular materials reported by $\mathrm{Gu}$ et al. [19] and recycled construction wastes reported by Azam et al. [20].

In addition to the experimental studies, the prediction model contributes to a better understanding of the $M_{R}$ of subgrade soils. According to previous study, some representative models are available for $M_{R}$ prediction. Hicks et al. [21] indicated that the stress level is the main factor affecting the $M_{R}$ of materials and developed the $k-\theta$ model containing only the bulk stress, as shown in the following equation:

$$
M_{R}=k_{1} \theta^{k_{2}}
$$

where $\theta$ is the bulk stress, $\theta=\sigma_{1}+\sigma_{2}+\sigma_{3}, \sigma_{1}, \sigma_{2}$, and $\sigma_{3}$ are the major principal stress, the intermediate principal stress, and the confining pressure, respectively, and $k_{1}$ and $k_{2}$ are regression coefficients.

Lytton et al. [22] adopted the octahedral shear stress to characterize the shear effect, and the model was finally embodied in AASHTO 2002, as shown in the following equation:

$$
M_{R}=k_{1} P_{a}\left(\frac{\theta}{P_{a}}\right)^{k_{2}}\left(\frac{\tau_{\mathrm{oct}}}{P_{a}}+1\right)^{k_{3}}
$$

where $P_{a}=101.3 \mathrm{kPa}$, which is the atmospheric pressure; $\tau_{\text {oct }}$ is the octahedral shear stress, $\tau_{\text {oct }}=(\sqrt{2} / 3) \sigma_{d}, \sigma_{d}=\sigma_{1}-\sigma_{3}$ is the deviator stress; $k_{3}$ is the regression coefficient.

Several scholars proposed that the influence of humidity state on the $M_{R}$ should be directly reflected in the prediction model. Hence, the humidity parameter commonly employed in unsaturated soils mechanics, that is, the matric suction, was widely included in the prediction models. Liang et al. [23] believed the matric suction has the confinement impact, such as the bulk stress, so the matric suction and the bulk stress were combined into the same term, as shown in the following equation:

$$
M_{R}=k_{1} P_{a}\left(\frac{\theta+\chi \psi}{P_{a}}\right)^{k_{2}}\left(\frac{\tau_{\mathrm{oct}}}{P_{a}}+1\right)^{k_{3}},
$$

where $\chi$ is the effective stress parameter $(\chi \in[0,1]$, determined by the properties of different materials); $\psi$ is the matric suction, $\psi=u_{a}-u_{w}, u_{a}$ is the pore-air pressure, and $u_{w}$ is the pore-water pressure.

Given that the bulk stress could not separate the constraint effect and shear effect because the bulk stress contains the confining stress and maximum cyclic stress, Yao et al. [15] defined the minimum bulk stress $\theta_{m}$ and built

$$
M_{R}=k_{1} P_{a}\left(\frac{\psi}{P_{a}}+1\right)^{k_{2}}\left(\frac{\theta_{m}}{P_{a}}\right)^{k_{3}}\left(\frac{\tau_{\mathrm{oct}}}{P_{a}}+1\right)^{k_{4}}
$$

where $\theta_{m}=\sigma_{1}+\sigma_{2}+\sigma_{3}-\sigma_{d}=3 \sigma_{3}$ is the minimum bulk stress; $k_{4}$ is the regression coefficient.

Zhang et al. [18], based on the laws obtained from the RLT tests of construction and demolition wastes, established the model that can consider the number of freeze-thaw cycles, compactness, humidity state, and stress state as shown in the following equation:

$$
M_{R}=k_{1} P_{a}[\ln (N+e)]^{k_{2}} C^{k_{3}}\left(\frac{\psi}{P_{a}}+1\right)^{k_{4}}\left(\frac{\theta_{m}}{P_{a}}\right)^{k_{5}}\left(\frac{\tau_{\mathrm{oct}}}{P_{a}}+1\right)^{k_{6}},
$$

where $N$ is the number of freeze-thaw cycles; $C$ is the compactness; and $k_{5}$ and $k_{6}$ are regression coefficients.

In general, the related studies provided insightful and constructive comments into the influence of humidity state on $M_{R}$ of subgrade soils. However, to the best of the authors' knowledge, due to rainwater infiltration and lateral migration, and transpiration during high temperature periods, the humidity of subgrade soils is not increasing continuously but undergoes intricate wetting and drying processes and finally reaches an equilibrium state. Therefore, the specimens were directly prepared with the final equilibrium moisture content and the tests conducted failed to accurately fit the actual humidity change process of the subgrade soils. Also, limited by the cumbersome and time-consuming test process $[24,25]$, it is inconvenient to use the matric suction as the humidity parameter. Furthermore, there are few reports on the prediction model of $M_{R}$ considering the repeated wetting-drying (WD) cycles.

To address the above problems, the subgrade soils were investigated through a series of WD cycles tests and RLT tests. From the experimental results, the influences of stress state, humidity state, and WD cycles on the $M_{R}$ were analyzed. On this basis, the prediction model of the $M_{R}$ that can consider repeated WD cycles was established and verified. The main findings of this study were summarized in the last section, which can supply novel contributions and technical supports to the theory for pavement design.

\section{Experiments Approach}

2.1. Materials and Specimens. The studied soils in this study were from Changsha City, Hunan Province, China. The particle size analysis is listed in Figure 1. The standard heavy compaction tests were conducted to acquire the OMC and maximum dry density of the soils. In accordance with the Chinese Guidance for Test Methods of Soils on Highway Engineering, other main basic physical properties had also been determined in Table 1. Based on these parameters, the soils were named as high liquid limit silts $(\mathrm{MH})$ according to the Unified Soils Classification System. 


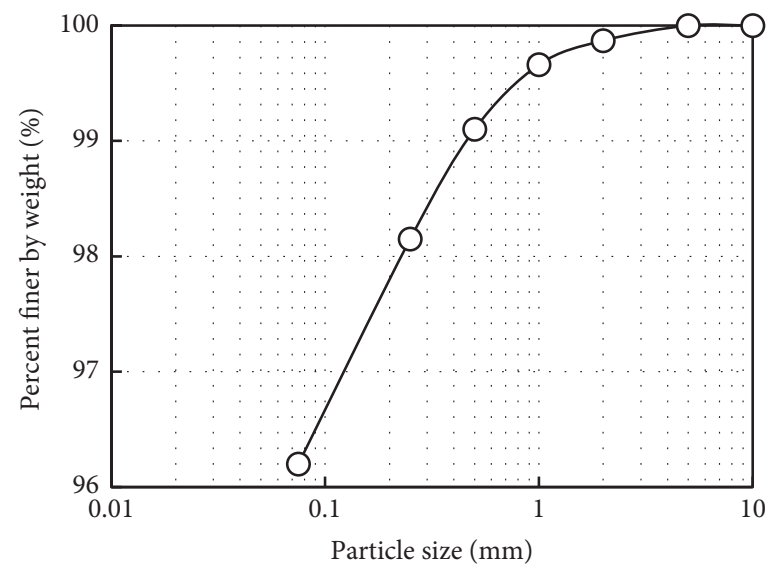

FIgURE 1: Distribution curves of particle size.

TABle 1: Basic physical properties of the used soils.

\begin{tabular}{lccccc}
\hline Liquid limit (\%) & Plastic limit (\%) & Plastic index & Maximum dry density & Optimum moisture content (\%) & Specific gravity \\
\hline 51.7 & 37.1 & 14.6 & $1.62 \mathrm{~g} / \mathrm{cm}^{3}$ & 22.6 & 2.71 \\
\hline
\end{tabular}

To ensure consistent compactness and humidity levels between specimens, all the soils were prepared in the laboratory. Firstly, the soils were crushed and collected after filtering by the $5 \mathrm{~mm}$ sieve and then dried at $105^{\circ} \mathrm{C}$ for $12 \mathrm{~h}$. Subsequently, the dry soils were mixed with distilled water under the OMC in order to simulate the initial humidity state of soils during subgrades filling [26] and then stored in a sealed plastic bag for $24 \mathrm{~h}$ so that the moisture was uniform. Meanwhile, the compactness of the specimens was set to $96 \%$ based on China's current requirements for road beds. Afterwards, the wet soils with the calculated mass were compacted by five layers into a cylinder that was $100 \mathrm{~mm}$ in diameter and $200 \mathrm{~mm}$ in height. Finally, the specimens were wrapped to avoid water evaporation.

2.2. Wetting-Drying Cycles. At present, the common practice to achieve WD cycles is to soak the specimens in water to the target wet side moisture content and then place them in the oven to dry at high temperature to the target dry side moisture content $[27,28]$. Although this pattern speeds up the test process, the water absorption and dehydration of the specimens are obviously much faster than the actual water exchange rate of subgrade soils. To this end, this study applied a novel method as shown in Figure 2; that is, the specimens were set in the diffuse misty air generated by the atomizer to absorb water and add humidity by capillary action. After the moisture content of the specimens reached the target value, they were transferred to an oven with an internal temperature of $50^{\circ} \mathrm{C}$ for drying. Such a way is more suitable for depicting the wetting and drying condition of soils on site.

Given the possible variation range of the equilibrium humidity state of the subgrade soils, the final actual moisture contents of specimens were set to 0.9 OMC, OMC, 1.1 OMC, 1.2 OMC, and 1.3 OMC, respectively. The specimens prepared under OMC were first humidified to $1.3 \mathrm{OMC}$ and then dehumidified to $0.9 \mathrm{OMC}$. The two parts were regarded as one WD cycle, and then so on. The numbers of WD cycles in this study were designed as $0,1,3$, and 5 . After the specimens have experienced the preset WD cycles, they changed from 0.9 OMC to the anticipant target moisture content. Taking the WD cycles 3 times and the final actual moisture content of 1.2 OMC as an example, the humidity change path is as follows: $\mathrm{OMC} \longrightarrow 1.3 \mathrm{OMC} \longrightarrow 0.9$ $\mathrm{OMC} \longrightarrow 1.3 \mathrm{OMC} \longrightarrow 0.9 \mathrm{OMC} \longrightarrow 1.3 \mathrm{OMC} \longrightarrow 0.9$ $\mathrm{OMC} \longrightarrow 1.2 \mathrm{OMC} \longrightarrow$ wrapped and allowed to stand for 1-2 days $\longrightarrow$ RLT tests. In order to determine the key nodes when the humidification moisture content $\left(w_{w}\right)$ and the dehumidification moisture content $\left(w_{D}\right)$ of the specimens reached the target level, it is necessary to grasp the humidity change rate. In this study, the specimens were weighed every about $10 \mathrm{~h}$, and the results are summarized in Figure 3. Based on this finding, the moment when the humidity of the specimen reached the target value can be estimated, namely, the weighing frequency can be increased for some time before this moment to control the required moisture content of the specimen.

2.3. Repeated Loading Triaxial Tests. DYNATRIAX-100/14, the dynamic triaxial test equipment, was used to measure the $M_{R}$ of specimens in this study. The load form adopted halfsine wave, the frequency was $1 \mathrm{~Hz}$, the action time was $0.2 \mathrm{~s}$, and the intermittent time was $0.8 \mathrm{~s}$. The stress conditions referred to the RLT sequence for subgrade fine-grained soils proposed by Luo [29], as shown in Table 2, benefiting from its comprehensive coverage of the stress range of the subgrade work area in China. In this sequence, the deviator stresses were designed as four groups from low to high, and the confining pressures in each group were divided into four levels from great to small so as to reduce the possibility of premature failure of the specimens during the loading process. The test data of the last five cycles in each stress combination are to acquire the corresponding $M_{R}$ value. 


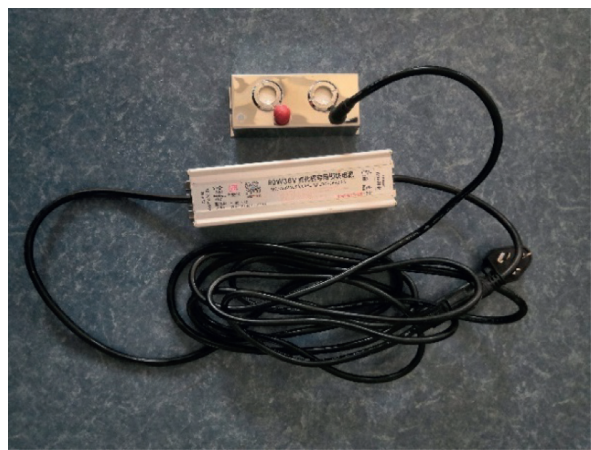

(a)

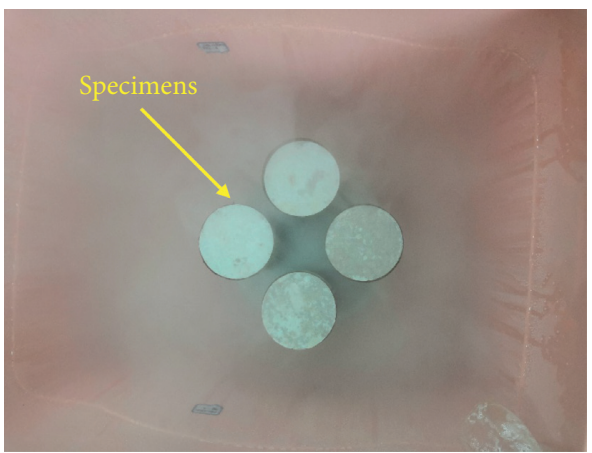

(b)

FIgURE 2: The atomization and humidification process of the specimens. (a) Atomizer. (b) Humidification.

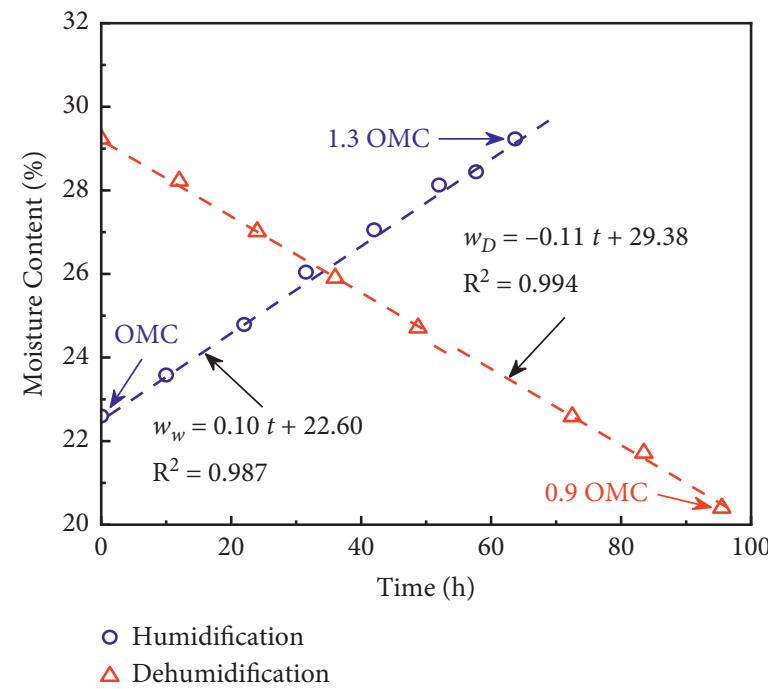

FIgURE 3: The relationship between $w_{w}$ and $w_{D}$ and time (t), respectively.

TABLE 2: The stress-loading sequence in this study.

\begin{tabular}{|c|c|c|c|c|c|}
\hline No. & $\begin{array}{c}\text { Confining pressure } \\
\sigma_{3}(\mathrm{kPa}) \\
\end{array}$ & $\begin{array}{c}\text { Contact pressure } 0.2 \\
\sigma_{3}(\mathrm{kPa}) \\
\end{array}$ & $\begin{array}{c}\text { Deviator stress } \\
\sigma_{d}(\mathrm{kPa}) \\
\end{array}$ & $\begin{array}{c}\text { Principal stress ratio } \\
\qquad \sigma_{1 /} \sigma_{3}\end{array}$ & Number of cycles \\
\hline 0 (preloading) & 30 & 6 & 55 & 2.8 & 2000 \\
\hline 1 & 60 & 12 & 30 & 1.5 & 100 \\
\hline 2 & 40 & 9 & 30 & 1.8 & 100 \\
\hline 3 & 30 & 6 & 30 & 2.0 & 100 \\
\hline 4 & 15 & 3 & 30 & 3.0 & 100 \\
\hline 5 & 60 & 12 & 55 & 1.9 & 100 \\
\hline 6 & 40 & 9 & 55 & 2.4 & 100 \\
\hline 7 & 30 & 6 & 55 & 2.8 & 100 \\
\hline 8 & 15 & 3 & 55 & 4.7 & 100 \\
\hline 9 & 60 & 12 & 75 & 2.3 & 100 \\
\hline 10 & 40 & 9 & 75 & 2.9 & 100 \\
\hline 11 & 30 & 6 & 75 & 3.5 & 100 \\
\hline 12 & 15 & 3 & 75 & 6.0 & 100 \\
\hline 13 & 60 & 12 & 105 & 2.8 & 100 \\
\hline 14 & 40 & 9 & 105 & 3.6 & 100 \\
\hline 15 & 30 & 6 & 105 & 4.5 & 100 \\
\hline 16 & 15 & 3 & 105 & 8.0 & 100 \\
\hline
\end{tabular}




\section{Analysis of Influence Factors of the Dynamic Resilient Modulus}

3.1. Influence of Deviator Stress on the Dynamic Resilient Modulus. Figure 4 shows the variation of $M_{R}$ with deviator stress under different confining pressures and moisture content before WD cycles. It can be observed that $M_{R}$ decreases with the enhancement of deviator stress. The possible principle behind this phenomenon is that the growth of the deviator stress leads to an increase in the vertical strain, and the increase of the vertical strain is greater than the increase of the deviator stress, which ultimately leads to a decrease in $M_{R}$. Taking the event of confining pressure of $30 \mathrm{kPa}$ and moisture content of 1.1 OMC as an example, when the deviator stress rises from $30 \mathrm{kPa}$ to $55 \mathrm{kPa}, 75 \mathrm{kPa}$, and $105 \mathrm{kPa}, M_{R}$ attenuates by $12.03 \%, 14.18 \%$, and $30.55 \%$, respectively. Obviously, the soils specimens presented softening behavior, which is consistent with the previous findings of many researchers $[14,15]$. It is worth pointing out that because $\tau_{\text {oct }}=(\sqrt{2} / 3) \sigma_{d}$, the octahedral shear stress and deviator stress have the same influence rule on the $M_{R}$.

3.2. Influence of Confining Pressure on the Dynamic Resilient Modulus. Figure 5 reveals the nonlinear positive correlation between $M_{R}$ and the confining pressure with various moisture content and deviator stress at WD cycle 1 time. For instance, under the deviator stress of $75 \mathrm{kPa}$ and the moisture content of $0.9 \mathrm{OMC}$, as the confining pressure gradually increases from $15 \mathrm{kPa}$ to $30 \mathrm{kPa}, 40 \mathrm{kPa}$, and $60 \mathrm{kPa}, M_{R}$ value expands $19.74 \%, 28.95 \%$, and $43.42 \%$ respectively. It can be seen that the confining pressure has a considerable lateral restraint effect on the specimens, so that it has a better stiffness holding capacity to resist vertical deformation under a higher deviator stress, in agreement with the results obtained in the past few decades $[14,16,30]$. Similarly, according to the equivalence relationship $\theta_{m}=3 \sigma_{3}$, the minimum bulk stress and confining pressure also have the coincident influence on the $M_{R}$.

3.3. Influence of Moisture Content on the Dynamic Resilient Modulus. Figure 6 illustrates that, under the given stress states, the humidification effect significantly reduces the $M_{R}$ of the specimens. For example, for the case of WD cycles 5 times and the confining pressure of $40 \mathrm{kPa}$, as the moisture content increases from 0.9 OMC to $1.3 \mathrm{OMC}$, the attenuation range of $M_{R}$ with various deviator stresses is $43.02 \%-67.35 \%$. It shows that the increased humidity causes the specimens to soften. The possible explanation is that water has a certain lubricating effect among soils particles. When the moisture content decreases, the water film on the surface of the soils particles is thinner, and the relative movement between the soils particles is more difficult, so the specimens have a stronger ability to resist deformation. Conversely, the increase in moisture content makes the relative movement between soils particles simpler, and the specimens are less resistant to deformation; namely, the stiffness is reduced.
3.4. Influence of Wetting-Drying Cycles on the Dynamic Resilient Modulus. In order to intuitively reflect the impact of repeated WD cycles on the $M_{R}$, referring to the way that Zhang et al. [18] defined the freeze-thaw damage factor, this study employed the WD damage factor as the evaluation indicator, as shown in the following equation:

$$
D=\frac{M_{R(0)}-M_{R(i)}}{M_{R(0)}},
$$

where $D$ is the WD damage factor; $M_{R(0)}$ is $M_{R}$ before WD cycles; $M_{R(i)}$ is $M_{R}$ after the $i$ times WD cycles, and $i=0,1,3$, 5 here.

Figure 7 indicates that, under the given moisture content and stress state, the damage factor increases with the accumulation of WD cycles. In particular, the attenuation of $M_{R}$ is the most obvious by the first WD effect, and the damage factor ranges from 0.27 to 0.54 . With the increase of the numbers of WD cycles, the growth rate of the damage factor gradually slows down and finally basically stabilizes. At the same time, the damage factor of $M_{R}$ after WD cycles 5 times is 0.63 to 0.95 . Compared with the 3 th cycle of $\mathrm{WD}$ cycles, the increase of the damage factor is less than $10 \%$. It can be considered that the stiffness of the specimen is stable after 5 WD cycles.

Annotation: $(60 \mathrm{kPa}, 30 \mathrm{kPa})$ denotes that the confining pressure is $60 \mathrm{kPa}$, and the deviator stress is $30 \mathrm{kPa}$. For clarity, only partial test results under various stress states are given.

\section{Prediction Model for the Dynamic Resilient Modulus with Wetting-Drying Cycles}

This section aims to establish a phenomenological model of the $M_{R}$ that can consider the WD cycles. A satisfactory prediction model should comprehensively include influencing factors and reasonably reflect the influence law of each factor on $M_{R}$ [31]. Based on the analysis in the previous section, the numbers of WD cycles, actual moisture content, minimum bulk stress, and octahedral shear stress are selected as independent variables. In particular, the actual moisture content is used instead of matric suction to characterize the humidity state, and the rewritten exponential form is applied to reflect the WD cycles impact, the established model as shown in (7). A total of $4 \times 5 \times 16$ (the numbers of WD cycles $\times$ the actual moisture content levels $\times$ the stress states) $=320$ sets of tests data in this study were used to fit the model, and the results were summarized in Table 3.

$$
M_{R}=k_{1} P_{a} e^{k_{2} N}\left(\frac{w}{\mathrm{OMC}}\right)^{k_{3}}\left(\frac{\theta_{m}}{P_{a}}\right)^{k_{4}}\left(\frac{\tau_{\mathrm{oct}}}{P_{a}}+1\right)^{k_{5}}
$$

where $N$ is the numbers of WD cycles; $w$ is the actual moisture content; $k_{1} \sim k_{5}$ are the model parameters, and other symbols have the same meaning as above.

For the fit result, $k_{1}$ is the coefficient which must be a positive number because $M_{R}$ cannot be negative. $k_{2}$ as an exponent must be a negative number, because with the growth of the number of WD cycles, $M_{R}$ reduces. $k_{3}$ should 


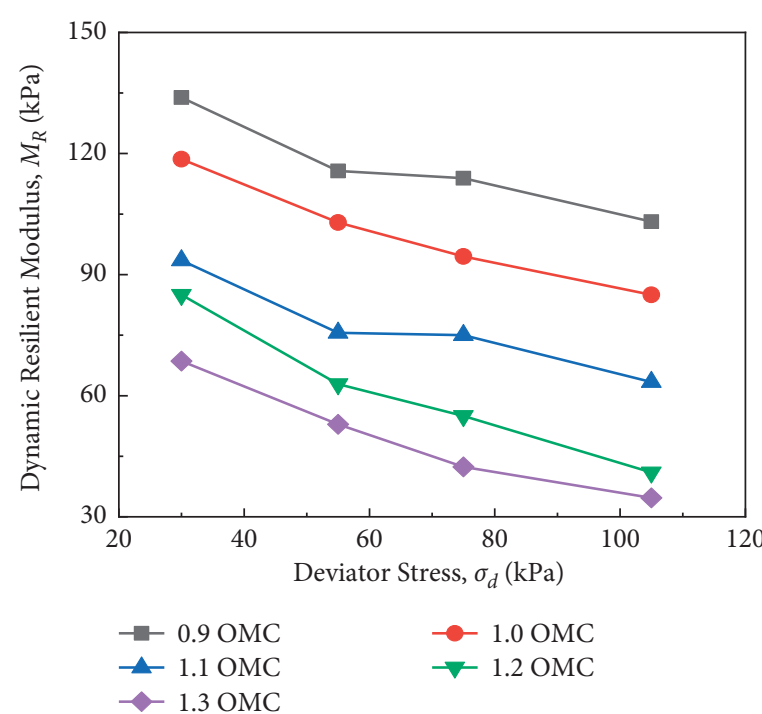

(a)

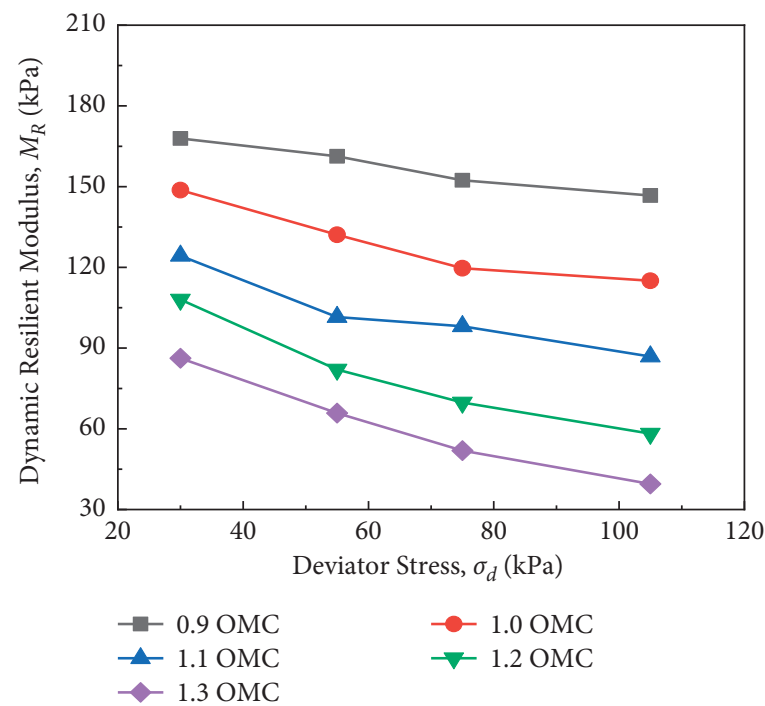

(c)

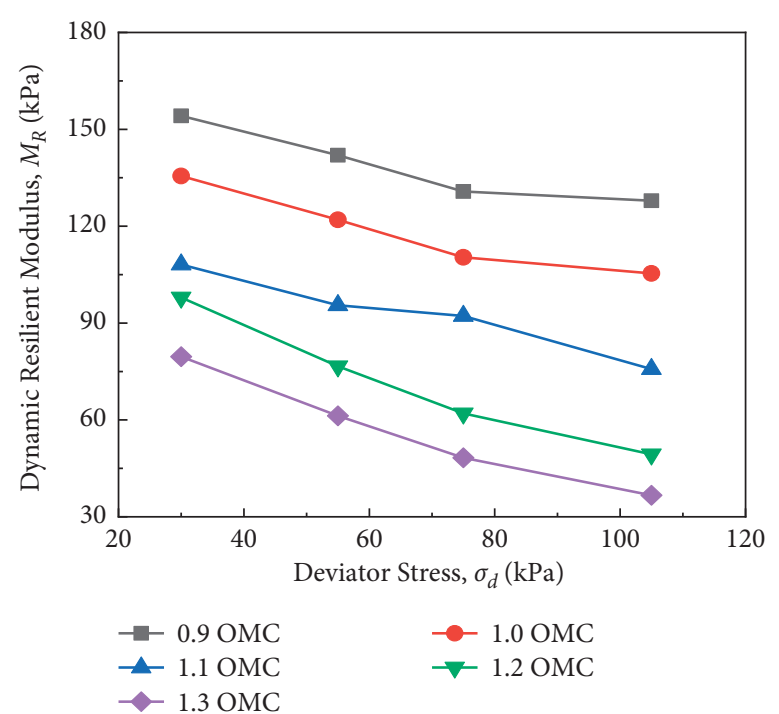

(b)

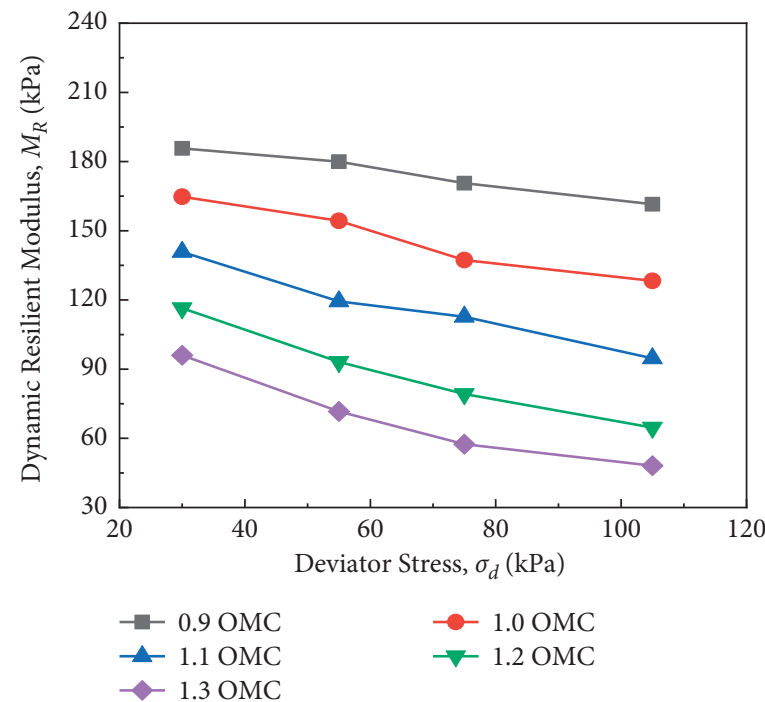

(d)

Figure 4: The relationship between $\sigma_{d}$, moisture content, and $M_{R}$ at WD cycles $=0$. (a) $\sigma 3=15 \mathrm{kPa}$. (b) $\sigma 3=30 \mathrm{kPa}$. (c) $\sigma 3=40 \mathrm{kPa}$. (d) $\sigma 3=60 \mathrm{kPa}$.

be a negative number, on account of the higher the actual moisture content, the smaller the $M_{R}$. According to the restraint effect caused by the minimum bulk stress and the softening effect produced by the octahedral shear stress on the soils specimens, it can be inferred that $k_{4}>0$ and $k_{5}<0$. Obviously, the results shown in Table 3 are consistent with the analysis of the experimental rules in this study. In addition, the value of the determination coefficient $R^{2}$ exceeds 0.9 , indicating that the prediction model exhibited in (7) is excellent. In order to have confidence in this model, this study is done in conjunction with relevant experimental data from other researchers to verify (7) [32], and the results are shown in Figure 8. It can be seen that the measured $M_{R}$ is close to the predicted value. Although $R^{2}$ is slightly lowered, this may be due to the difference in the actual process of the specimens being subjected to WD cycles, which leads to a decrease in the accuracy of (7), but the prediction effect is still excellent based on the recommended criteria for evaluating $R^{2}$ in road engineering [33-35]. Therefore, it can be speculated that this model is applicable to other soils although it is only proposed based on the high liquid limit silts taken from Changsha City, China, in this study. 


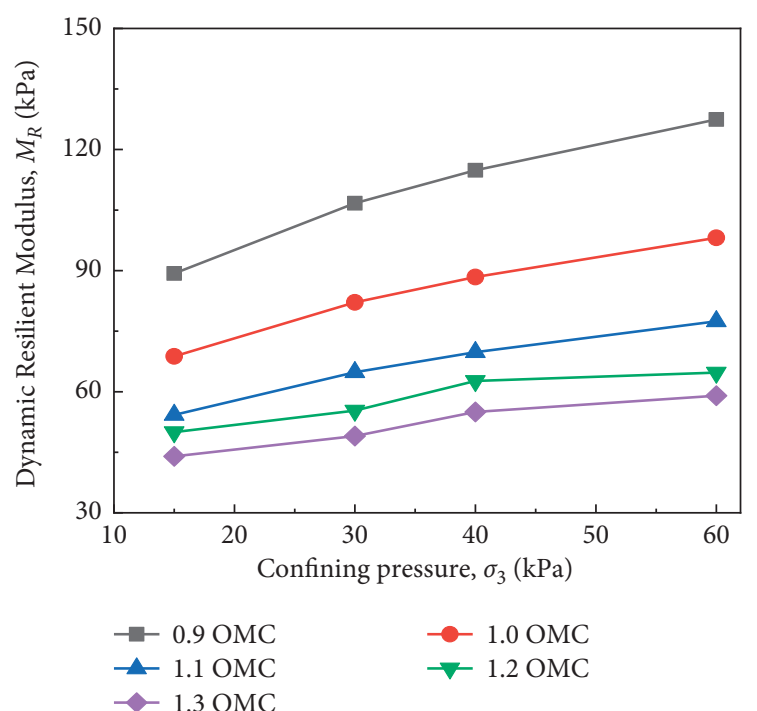

(a)

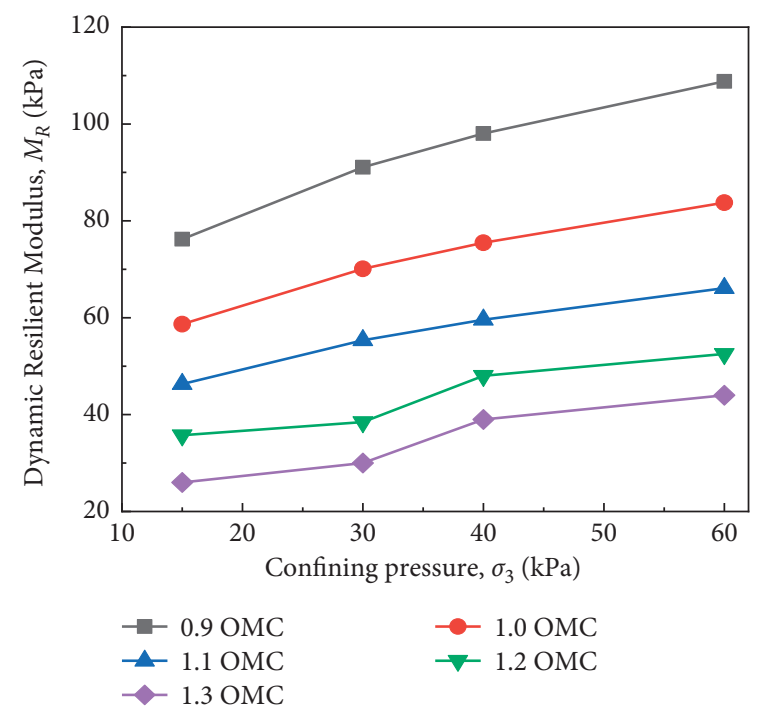

(c)

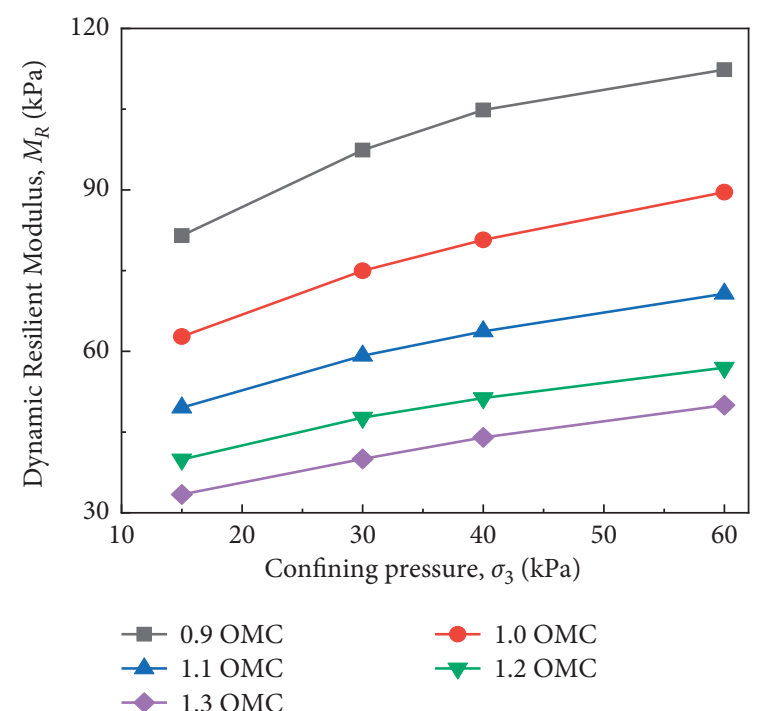

(b)

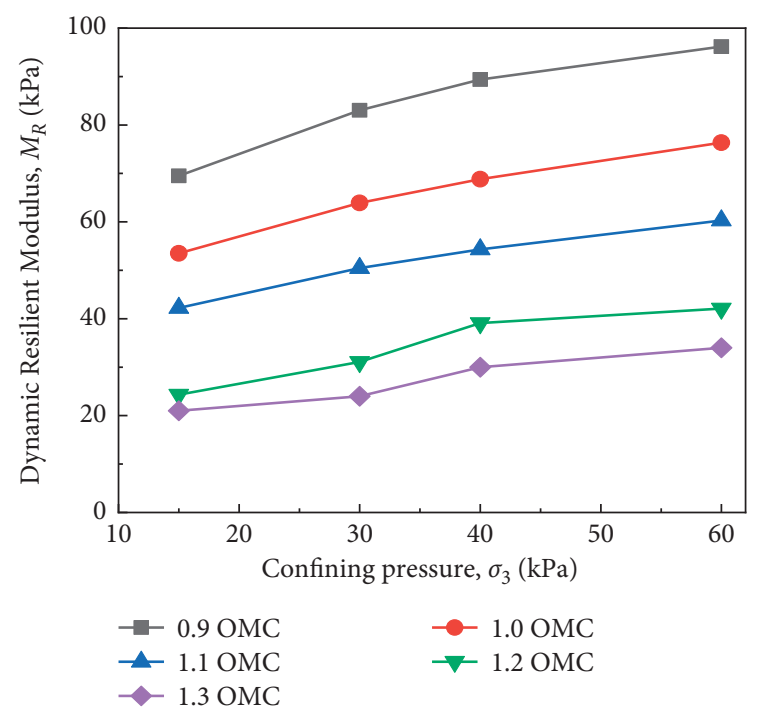

(d)

Figure 5: The relationship between $\sigma_{3}$, moisture content, and $M_{R}$ at WD cycles $=1$. (a) $\sigma_{d}=30 \mathrm{kPa}$. (b) $\sigma_{d}=55 \mathrm{kPa}$. (c) $\sigma_{d}=75 \mathrm{kPa}$. (d) $\sigma_{d}=105 \mathrm{kPa}$. 

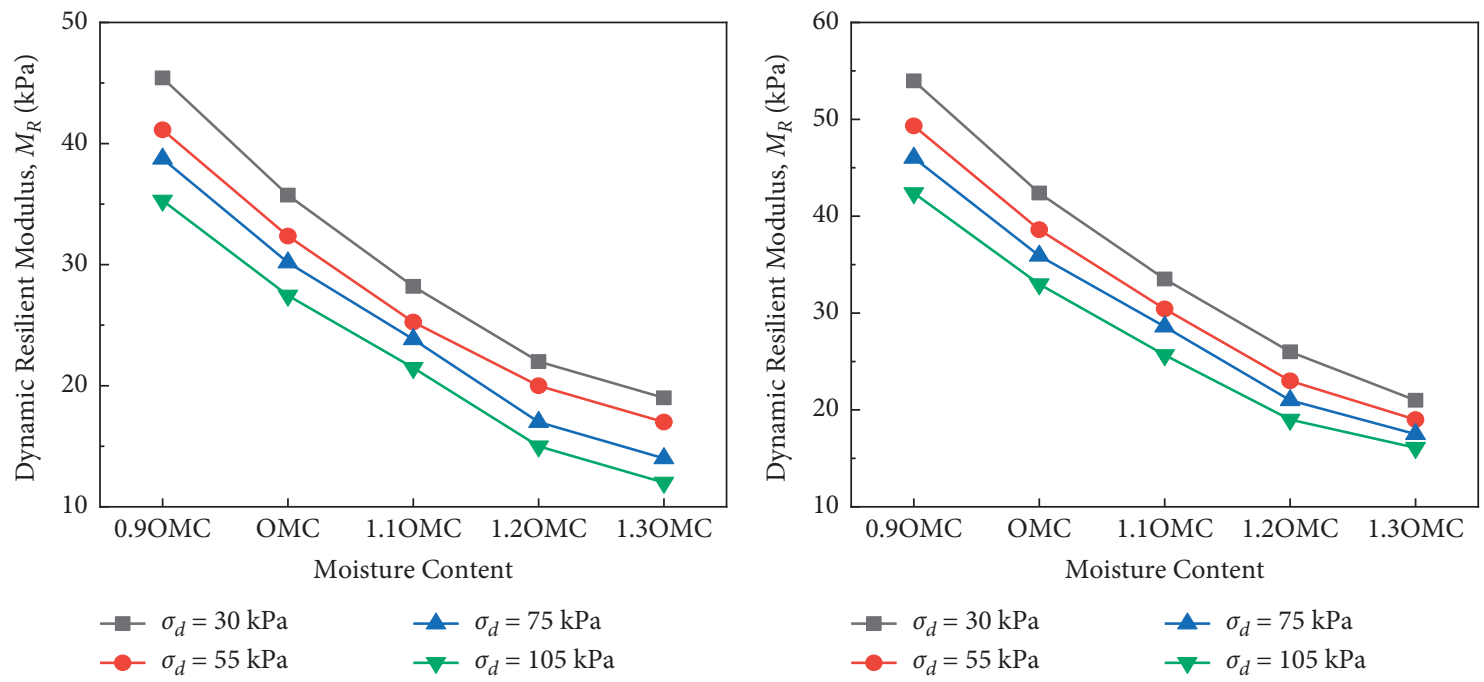

(a)

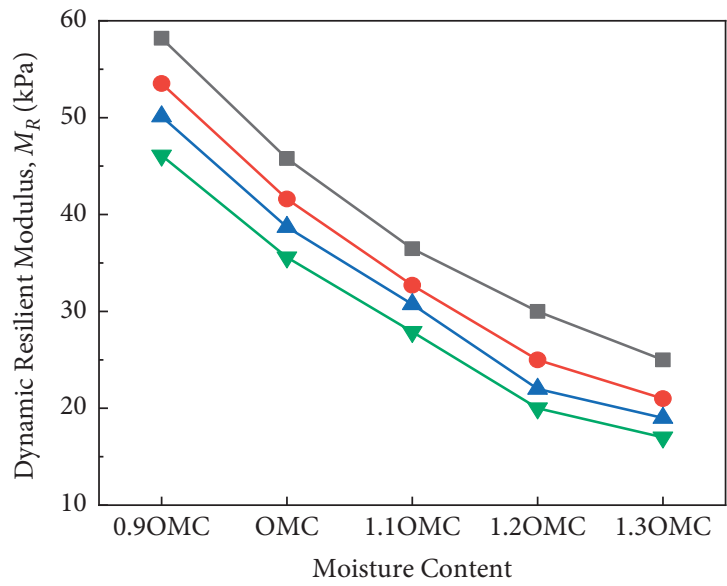

(b)

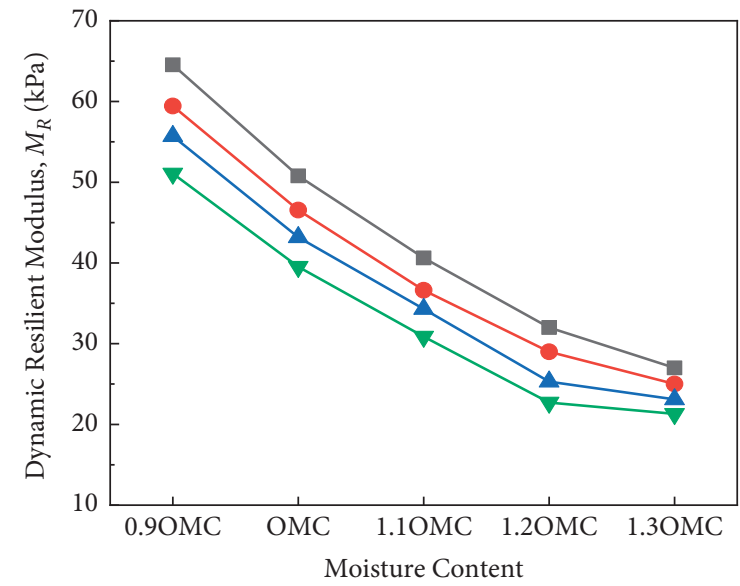

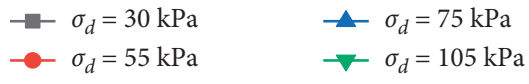

(c)

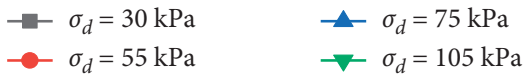

(d)

FIgUre 6: The relationship between $\sigma_{d}$, moisture content, and $M_{R}$ at WD cycles $=5$. (a) $\sigma_{3}=15 \mathrm{kPa}$. (b) $\sigma_{3}=30 \mathrm{kPa}$. (c) $\sigma_{3}=40 \mathrm{kPa}$. (d) $\sigma_{3}=60 \mathrm{kPa}$. 

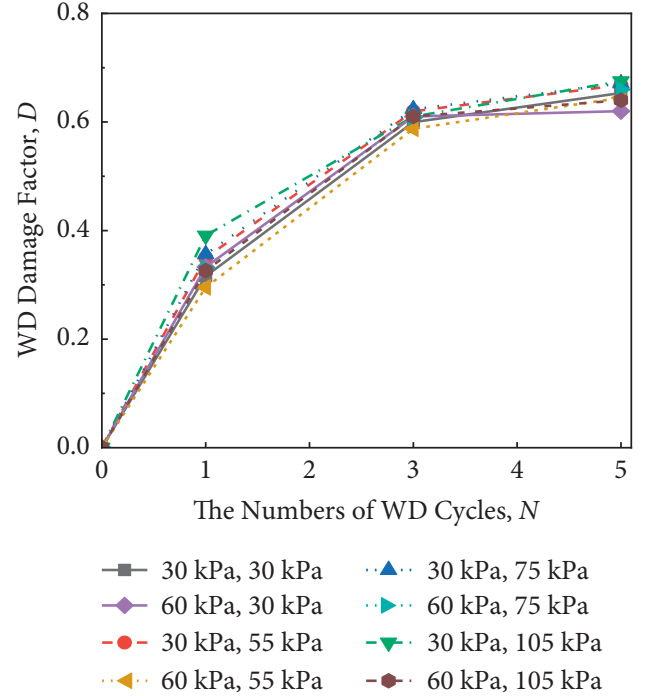

(a)

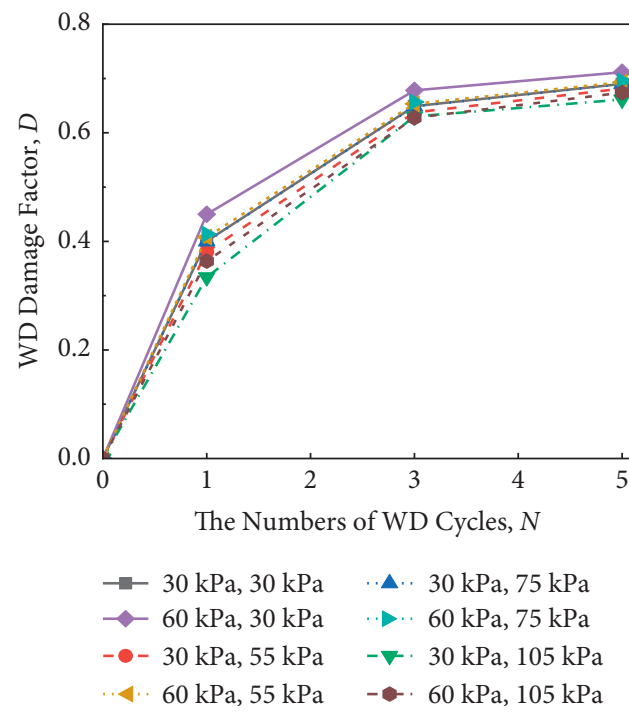

(c)
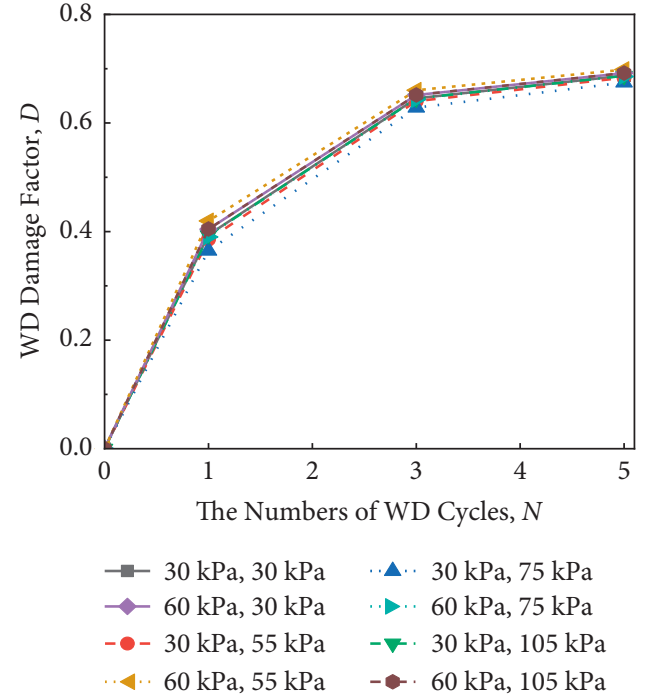

(b)

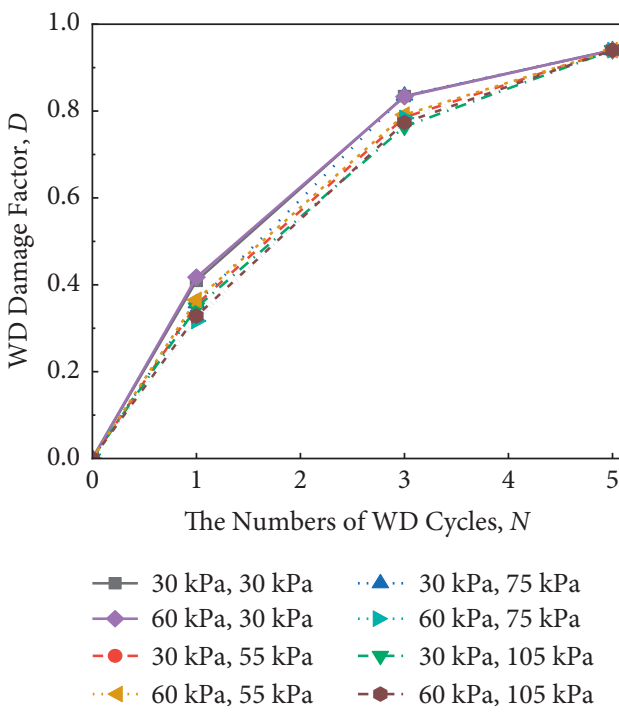

(d)

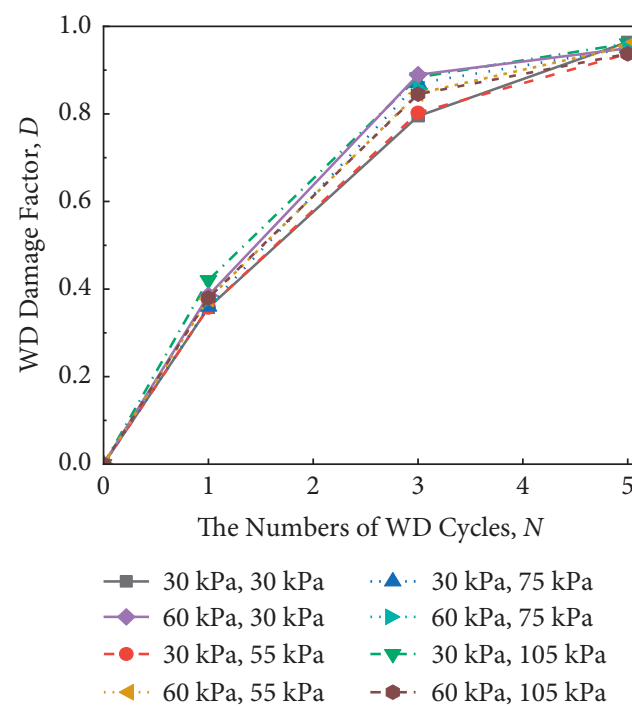

(e)

Figure 7: Damage factors of $M_{R}$ after WD cycles under different conditions. (a) 0.9 OMC. (b) OMC. (c) 1.1 OMC. (d) 1.2 OMC. (e) 1.3 OMC. 
TABLE 3: The fitting results of equation (7) in this study.

\begin{tabular}{cccccc}
\hline$k_{1}$ & $k_{2}$ & $k_{3}$ & $k_{4}$ & $k_{5}$ & $R^{2}$ \\
\hline 1.49 & -0.29 & -2.35 & 0.28 & -1.13 & 0.94 \\
\hline
\end{tabular}

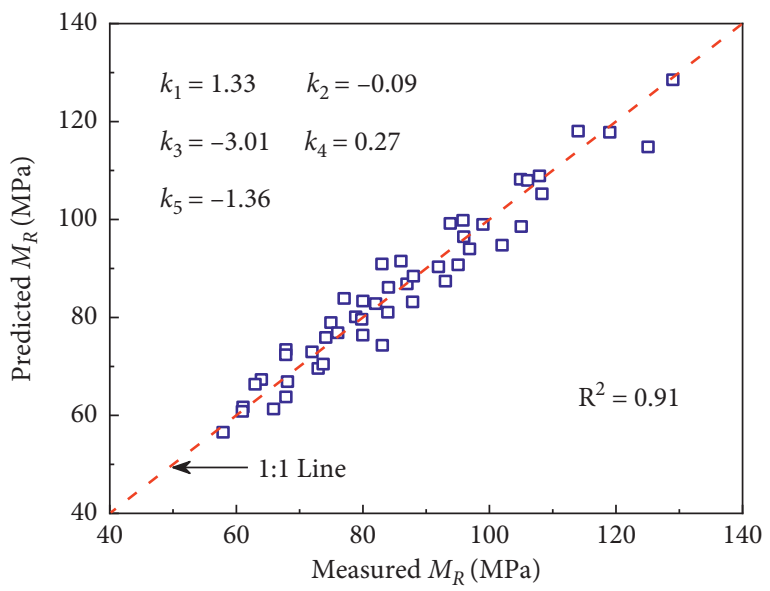

Figure 8: The predicted by equation (7) and measured $M_{R}$ in another studies.

\section{Conclusions}

This study aimed at revealing the influence of humidity state on $M_{R}$ of subgrade soils considering WD cycles. For this purpose, this study carried out a series of WD cycles and RLT tests. Based on the analysis of experimental results, the main findings of this research can be summarized as follows:

(1) The innovative humidification method was realized by using atomizer, which was more consistent with the actual WD cycles condition of subgrade soils. According to the exploratory tests, the change relationship between moisture content and time in the process of humidification and dehumidification of the specimens was mastered, so as to provide technical support for accurately controlling the key nodes of WD cycles.

(2) The stress state has a significant effect on the stiffness of subgrade soils; that is, $M_{R}$ decreased with the increase of deviator stress and increased with the rise of confining pressure. Meanwhile, the humidification due to the growth in moisture content led to a decrease in $M_{R}$. In addition, the accumulation of repeated WD cycles attenuated $M_{R}$, but the decay rate gradually slowed down until it stabilized after 5 WD cycles.

(3) This study employed the ratio of actual moisture content to OMC to characterize the humidity state, the improved exponential form reflected the influence of WD cycles, and the minimum bulk stress and octahedral shear stress embodied the constraint and shear effect, respectively. On this basis, a novel and excellent prediction model for $M_{R}$ of subgrade soils was established.
It is worth emphasizing that although the applicability of the proposed model to the data of other researchers is successful, the focus in the future should continue to search for more soils tests data for verification to ensure the robustness of the model.

\section{Data Availability}

Some or all data and models that support the findings of this study are available from the corresponding author upon reasonable request.

\section{Conflicts of Interest}

The authors declare that they have no conflicts of interest.

\section{Acknowledgments}

The authors gratefully acknowledge the program offered by the Shandong Hi-Speed Group Innovation Research Institute: Key technologies for green and intelligent construction of durable expressways (CYZX-JT-2020-05), and the financial support by the Science and Technology R\&D Project (2021-ZJKJ-QNCX17) from China Communications Construction Co., Ltd.

\section{References}

[1] J. Qian, Y. Yao, J. Li, H. Xiao, and S. Luo, "Resilient properties of soil-rock mixture materials: preliminary investigation of the effect of composition and structure," Materials, vol. 13, no. 7, Article ID 1658, 2020.

[2] J. Zhang, H. Fan, S. Zhang, J. Liu, and J. Peng, "Back-calculation of elastic modulus of high liquid limit clay subgrades based on viscoelastic theory and multipopulation Genetic algorithm," International Journal of Geomechanics, vol. 20, no. 10, Article ID 04020194, 2020.

[3] K. Zhang, W. Li, and F. Han, "Performance deterioration mechanism and improvement techniques of asphalt mixture in salty and humid environment," Construction and Building Materials, vol. 208, pp. 749-757, 2019.

[4] J. Li, J. Zhang, G. Qian, J. Zheng, and Y. Zhang, "Three-dimensional simulation of aggregate and asphalt mixture using parameterized shape and size gradation," Journal of Materials in Civil Engineering, vol. 31, no. 3, Article ID 04019004, 2019.

[5] Y. Yao, J. Li, C. Liang, J. Zheng, and F. Gu, "Effects of gravel content and shape on shear behaviour of soil-rock mixture: experiment and DEM modelling," Computers and Geotechnics, vol. 141, Article ID 104476, 2022.

[6] H. b Liu, S. Sun, H. b Wei, and W. j Li, "Effect of freeze-thaw cycles on static properties of cement stabilised subgrade silty soil," International Journal of Pavement Engineering, pp. 1-13, 2021.

[7] Y. Yao, J. Zheng, Z. Chen, J. Zhang, and Y. Li, "Field measurements and numerical simulations of temperature and moisture in highway engineering using a frequency domain reflectometry sensor," Sensors, vol. 16, no. 6, Article ID 857, 2016.

[8] J. Zhang, J. Peng, A. Zhang, and J. Li, "Prediction of permanent deformation for subgrade soils under traffic loading in Southern China," International Journal of Pavement Engineering, pp. 1-10, 2020. 
[9] S. Zhao and J. Liu, "Rutting evaluation of alaskan asphalt pavement containing sustainable materials," Journal of Testing and Evaluation, vol. 46, no. 4, pp. 1366-1375, 2018.

[10] H. Wei, J. Li, F. Wang, J. Zheng, Y. Tao, and Y. Zhang, "Numerical investigation on fracture evolution of asphalt mixture compared with acoustic emission," International Journal of Pavement Engineering, 2021.

[11] W. Liu, H. Lin, H. Guo et al., "An approach to investigate coarse aggregates movement of asphalt mixture based on wheel tracking test," Construction and Building Materials, vol. 309, no. 22, Article ID 125161, 2021.

[12] R. Elliott, "Selection of subgrade modulus for AASHTO flexible pavement design," Transportation Research Record, vol. 1354, pp. 39-44, 1992.

[13] J. Zhang, F. Li, L. Zeng, J. Peng, and J. Li, "Numerical simulation of the moisture migration of unsaturated clay embankments in southern China considering stress state," Bulletin of Engineering Geology and the Environment, vol. 80, no. 1, pp. 11-24, 2020.

[14] J. Zhang, J. Peng, J. Zheng, and Y. Yao, "Characterisation of stress and moisture-dependent resilient behaviour for compacted clays in South China," Road Materials and Pavement Design, vol. 21, no. 1, pp. 262-275, 2018.

[15] Y. Yao, J. Zheng, J. Zhang, J. Peng, and J. Li, "Model for predicting resilient modulus of unsaturated subgrade soils in south China," KSCE Journal of Civil Engineering, vol. 22, no. 6, pp. 2089-2098, 2018.

[16] Z. Han, S. K. Vanapalli, J. P. Ren, and W. L. Zou, "Characterizing cyclic and static moduli and strength of compacted pavement subgrade soils considering moisture variation," Soils and Foundations, vol. 58, no. 5, pp. 1187-1199, 2018.

[17] Y. Zhao, Z. Lu, H.-L. Yao, F. Gu, and Y.-H. Duan, "Experimental study of dynamic resilient modulus of subgrade soils under coupling of freeze-thaw cycles and dynamic load," Journal of Central South University, vol. 27, no. 7, pp. 20432053, 2020.

[18] J. Zhang, A. Zhang, C. Huang, H. Yu, and C. Zhou, "Characterising the resilient behaviour of pavement subgrade with construction and demolition waste under freeze-thaw cycles," Journal of Cleaner Production, vol. 300, Article ID 126702, 2021.

[19] F. Gu, H. Sahin, X. Luo, R. Luo, and R. L. Lytton, "Estimation of resilient modulus of unbound aggregates using performance-related base course properties," Journal of Materials in Civil Engineering, vol. 27, Article ID 04014188, 2015.

[20] A. M. Azam, D. A. Cameron, and M. M. Rahman, "Model for prediction of resilient modulus incorporating matric suction for recycled unbound granular materials," Canadian Geotechnical Journal, vol. 50, no. 11, pp. 1143-1158, 2013.

[21] R. G. Hicks and C. L. Monismith, "Factors influencing the resilient response of granular materials," Transportation Research Record, vol. 345, pp. 14-31, 1971.

[22] R. L. Lytton, J. Uzan, and E. G. Fernando, Development and Validation of Performance Prediction Models and Specifications for Asphalt Binders and Paving Mixes, Strategic Highway Research Program, 1993.

[23] R. Y. Liang, S. Rabab'ah, and M. Khasawneh, "Predicting moisture-dependent resilient modulus of cohesive soils using soil suction concept," Journal of Transportation Engineering, vol. 134, no. 1, pp. 34-40, 2008.

[24] Y. Yao, S. Luo, J. Qian, J. Li, H. Xiao, and X. Luo, "Soil-water characteristics of the low liquid limit silt considering compaction and freeze-thaw action," Advances in Civil Engineering, vol. 2020, Article ID 8823666, 3 pages, 2020.
[25] Y. Yao, J. Ni, and J. Li, "Stress-dependent water retention of granite residual soil and its implications for ground settlement," Computers and Geotechnics, vol. 129, Article ID 103835, 2021.

[26] J. Zhang, L. Ding, F. Li, and J. Peng, "Recycled aggregates from construction and demolition wastes as alternative filling materials for highway subgrades in China," Journal of Cleaner Production, vol. 255, Article ID 120223, 2020.

[27] X. Zhou, J. Hu, Y. Wei, and C. Cai, "Estimation of soil detachment capacity on steep slopes in permanent gullies under wetting-drying cycles," Catena, vol. 206, Article ID 105450, 2021.

[28] W. Liu, X. Tang, Q. Yang, and W. Li, "Influence of drying/ wetting cycles on the mechanical cyclic behaviours of silty clay," European Journal of Environmental and Civil Engineering, vol. 19, no. 7, pp. 867-883, 2014.

[29] Z. Luo, Study on dynamic resilient modulus of subgrade and granular layer, Ph.D. Thesis, Tongji University, Shanghai, China, 2007.

[30] J. Li, J. Zheng, Y. Yao, J. Zhang, and J. Peng, "Numerical method of flexible pavement considering moisture and stress sensitivity of subgrade soils," Advances in Civil Engineering, vol. 2019, Article ID 7091210, 10 pages, 2019.

[31] J. Zhang, J. Peng, L. Zeng, J. Li, and F. Li, "Rapid estimation of resilient modulus of subgrade soils using performance-related soil properties," International Journal of Pavement Engineering, vol. 22, no. 6, pp. 732-739, 2019.

[32] J. Ceratti, W. Gehling, and W. Núñez, "Seasonal variations of a subgrade soil resilient modulus in southern Brazil," Transportation Research Record, vol. 1874, pp. 165-173, 2004.

[33] J. Zhang, A. Zhang, J. Li, F. Li, and J. Peng, "Gray correlation analysis and prediction on permanent deformation of subgrade filled with construction and demolition materials," Materials, vol. 12, no. 18, Article ID 3035, 2019.

[34] Z. Han and S. Vanapalli, "State-of-the-art: prediction of resilient modulus of unsaturated subgrade soils," International Journal of Geomechanics, vol. 16, no. 4, Article ID 04015104, 2016.

[35] J. Zhang, J. Peng, J. Zheng, L. Dai, and Y. Yao, "Prediction of resilient modulus of compacted cohesive soils in south China," International Journal of Geomechanics, vol. 19, no. 17, Article ID 04019068, 2019. 